\title{
Primary retroperitoneal cystic mucinous carcinoma - case report and review of the literature
}

\author{
Gilani SNS ${ }^{1}$, Carr NJ ${ }^{2}$, Mustajab A ${ }^{2}$, Moran BJ ${ }^{1}$ \\ 1. Department of Colorectal Surgery, Basingstoke and North Hampshire Hospital, UK. 2. Department of Pathology, \\ Basingstoke and North Hampshire Hospital, UK.
}

Correspondence: Gilani SNS. Address: Department of Colorectal Surgery, Basingstoke and North Hampshire Hospital, UK. E-mail: drnadiagilani7@hotmail.com

Received: January 18, 2015

DOI : $10.5430 /$ crcp.v2n3p84

Accepted: April 6, 2015

Online Published: May 12, 2015

URL: http://dx.doi.org/10.5430/crcp.v2n3p84

\section{Abstract}

Primary retroperitoneal mucinous tumours (PRMTs) are rare and predominantly affect females. Due to the rarity of these tumours, histogenesis and management strategy are poorly defined. We report the case of a 29 years old female, who presented with abdominal pain and a palpable mass. Despite complete excision she presented within eight weeks with disseminated disease and a biopsy proven skin metastasis. Despite several courses of chemotherapy she succumbed within 5 months of initial diagnosis. The published literature is reviewed with relevance to the clinical diagnosis, histological assessment and management of this uncommon tumour.

\section{Key words}

Primary retroperitoneal mucinous tumours, Abdominal pain, Abdominal distension

\section{I ntroduction}

Primary retroperitoneal mucinous tumours (PRMT) are uncommon neoplasms, predominantly affecting females ${ }^{[1]}$. Because of the rarity their histogenesis and biological behaviour is not completely understood and optimal management therapy remains speculative. These tumours are categorized into three groups, mucinous cystadenoma, mucinous borderline tumours or tumours of low malignant potential and mucinous carcinomas ${ }^{[2]}$. The median age at diagnosis is 42 years and ranges from $17-86$ years ${ }^{[3]}$.

As a consequence of the retroperitoneal origin, clinical symptoms may only manifest when the tumour mass has progressed to a substantial size. The standard treatment is surgical resection and the role of adjuvant chemotherapy remains uncertain.

\section{Case report}

A 29 years old female presented with a one month history of lower abdominal pain and a rapid onset left lower quadrant palpable mass. There was nothing of relevance in her past medical history. There was a strong family history of cancer. The patient's mother had curative surgery for rectal cancer at a young age and her father had died in his 60's from 
lymphoma. Her maternal grandmother had ovarian cancer at the age of 80 years and paternal grandmother had breast cancer aged 70. Her paternal cousin had breast cancer aged 40 and maternal aunt had breast cancer. She was a non smoker with occasional alcohol intake. On examination she had a mobile palpable mass in the left lower quadrant. Her laboratory data was within normal limits including CEA $<0.5 \mu \mathrm{g}$ and CA-125: $5.1 \mathrm{u} / \mathrm{ml}$. Ultrasound and subsequent CT (see Figure 1) demonstrated an unilocular cystic mass measuring $13 \mathrm{~cm} \times 9.9 \mathrm{~cm} \times 7.8 \mathrm{~cm}$ in the left iliac fossa, displacing the descending colon anteriorly. There was no other abnormality on imaging and both ovaries were radiologically normal. At subsequent colonoscopy multiple small polyps in the rectum and sigmoid were detected and histology revealed adenomatous polyps with no malignancy.

Figure 1. Unilocular cystic mass measuring $13 \mathrm{~cm}$ $\times 9.9 \mathrm{~cm} \times 7.8 \mathrm{~cm}$ in the left iliac fossa

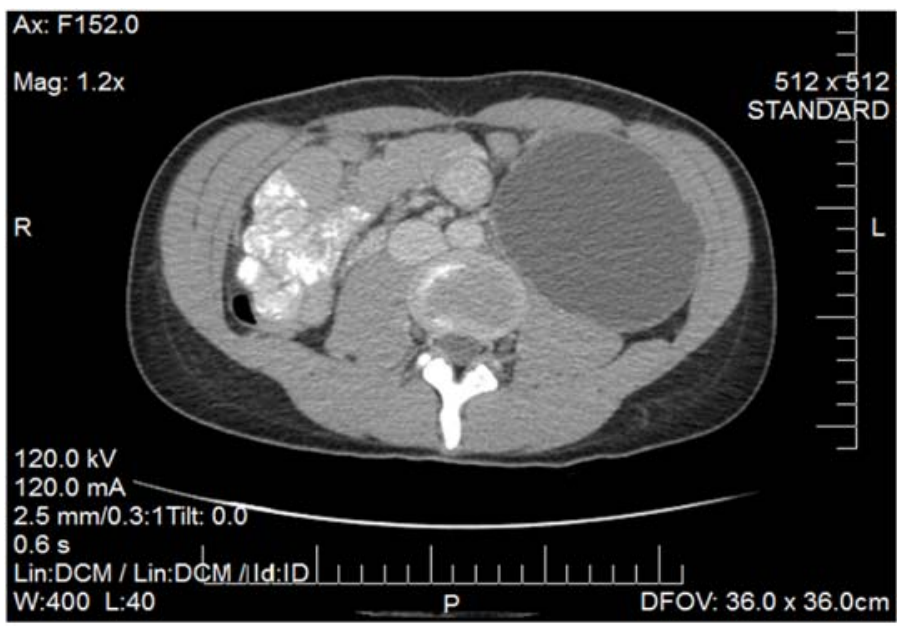

At laparotomy a large retroperitoneal mass was found behind the left colon separate from the colon with no connection to any other structure in the retro-peritoneum. The cystic mass was removed intact. Macroscopically, it was a unilocular cyst, $17 \mathrm{~cm}$ in greatest dimension, weighing $620 \mathrm{~g}$, with a thin wall containing light brown watery fluid. The external surfaces were smooth (see Figure 2) but there were papillary excrescences on its internal surfaces, the largest $20 \mathrm{~mm}$ in diameter.

Figure 2. Resected specimen

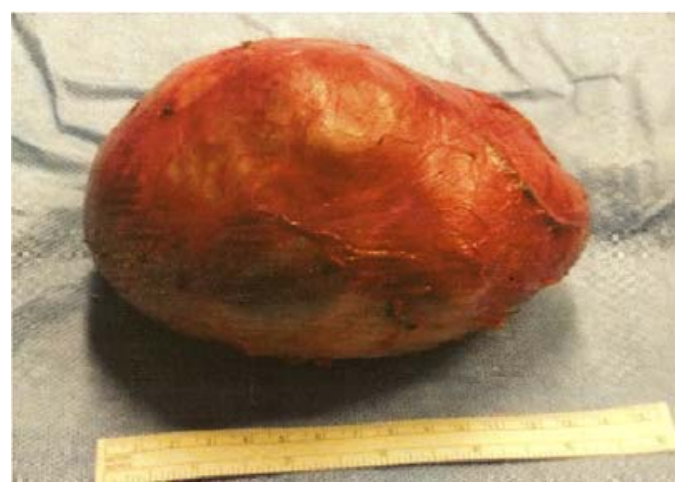

Microscopically, the cyst was lined by epithelium showing a variety of appearances (see Figure 3). In a few places the atypia was low grade and the features resembled a mucinous cystadenoma. In most areas, there was marked cytological atypia with scattered atypical mitoses; micropapillary projections were common (see Figure 3A), and the papillary excrescences were covered with similar epithelium (see Figure 3B). Intestinal differentiation with goblet cells was visible in many areas (see Figure 3C). In other areas, the differentiation was indeterminate. Cells resembling gastric foveolar cells were also present focally. Immunohistochemically, the tumour cells showed strong but patchy expression of CK7, CK20, CDX2 and CEA (see Figure 4). Occasional cells showed membranous CA-125 expression. There were small numbers of scattered cells exhibiting synaptophysin expression, consistent with neuroendocrine differentiation. There was no expression of calretinin, oestrogen receptor or progesterone receptor in the epithelium. Focal adenocarcinoma was present, characterised by invasion of the cyst wall by malignant cells (see Figure 3D). 

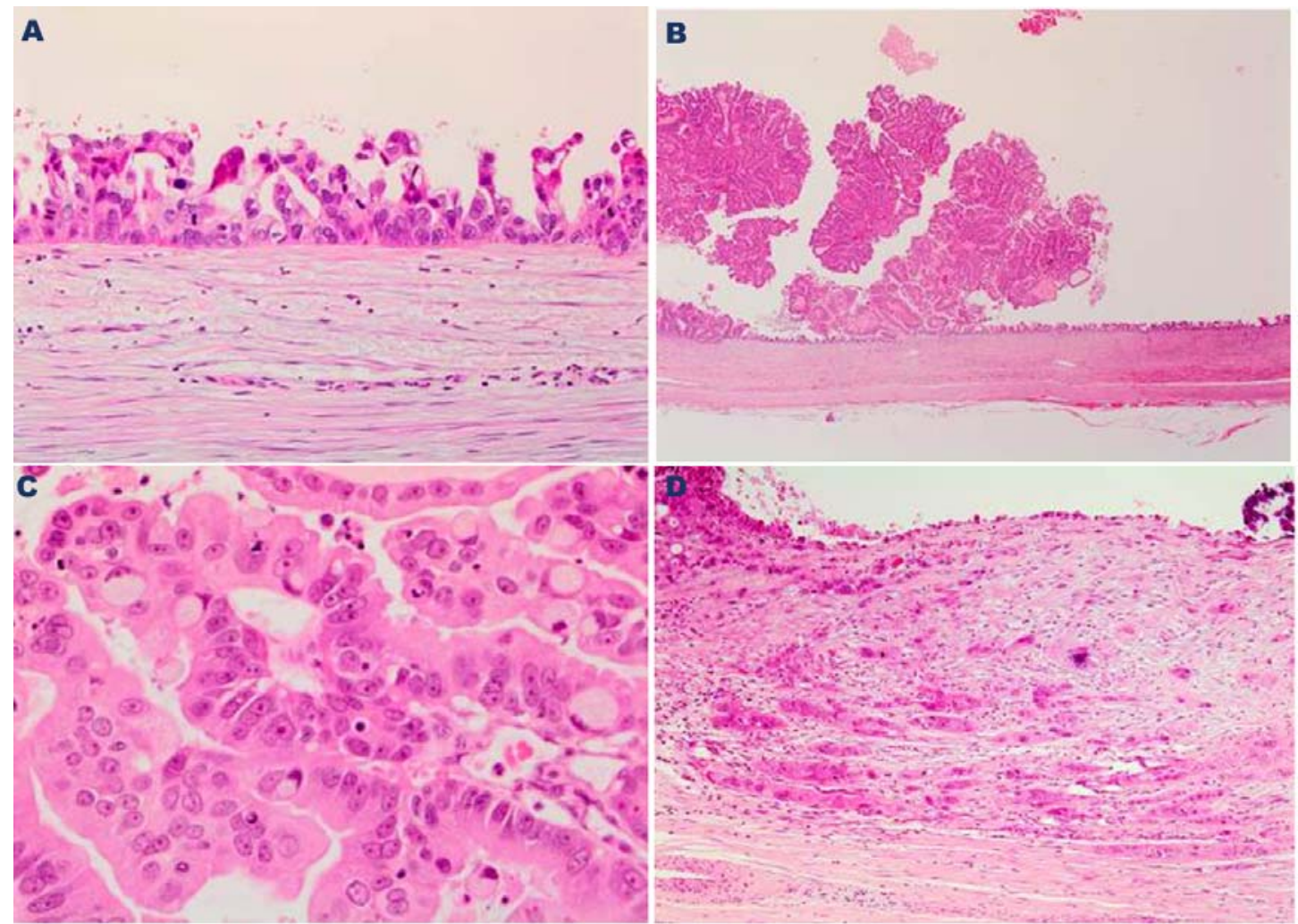

Figure 3. A. High grade epithelial dysplasia with micropapillary features. Haematoxylin and eosin, $\times 10$. B. A papillary excrescence. Haematoxylin and eosin, $\times 2$. C. Intestinal differentiation with goblet cells. Haematoxylin and eosin, $\times 40$. D. Adenocarcinoma invading the wall of the cyst. Haematoxylin and eosin, $\times 10$.

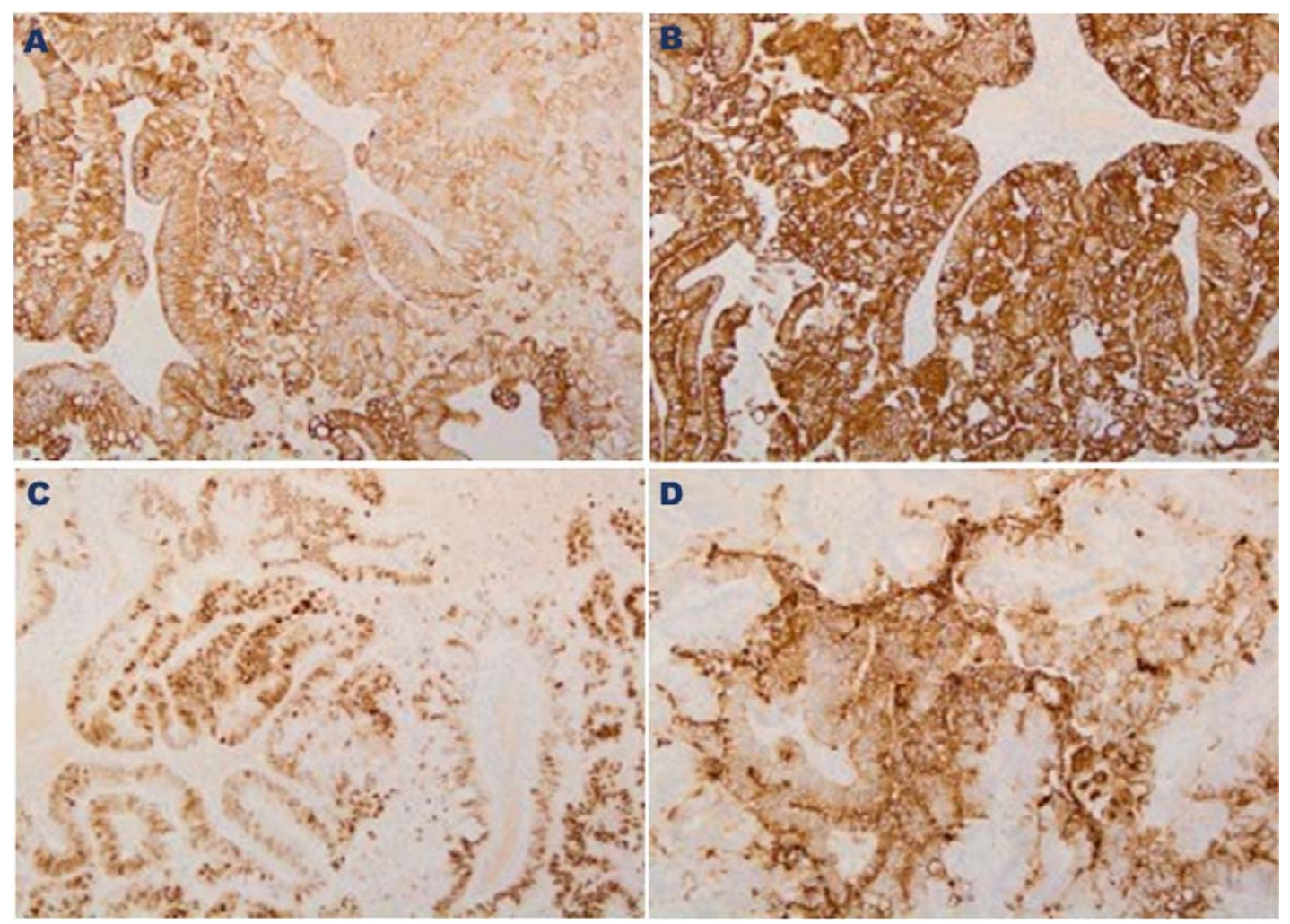

Figure 4. A. CK7, ×10. B. CK20, ×10. C. CDX2, ×10. D. CEA, ×10. 
The cyst wall was fibrous with flecks of calcification. No ovarian-type stroma was identified histologically. However, oestrogen receptor expression was observed in the stromal cells. She made a rapid and uneventful recovery. However she presented with back pain, generalised abdominal pain and chest pain within four weeks of surgery and then six weeks later developed a cutaneous nodule on the left side of her neck. Excisional biopsy revealed metastatic poorly differentiated adenocarcinoma. Repeat CT (see Figure 5) demonstrated widespread metastatic disease. Pulmonary nodules in the right hemithorax and a moderate right pleural effusion were noted with enlargement of mediastinal and left hilar lymph nodes and multiple liver metastases. Tumour markers revealed a normal CEA of 1.2 but CA125 (513 kU/L) and, CA19-9: (379 kU/L) were elevated. MRI of brain and spine confirmed widespread bony metastatic disease throughout the spine with no evidence of spinal cord compression and multiple intramuscular foci of metastatic disease.

Figure 5. Liver metastases

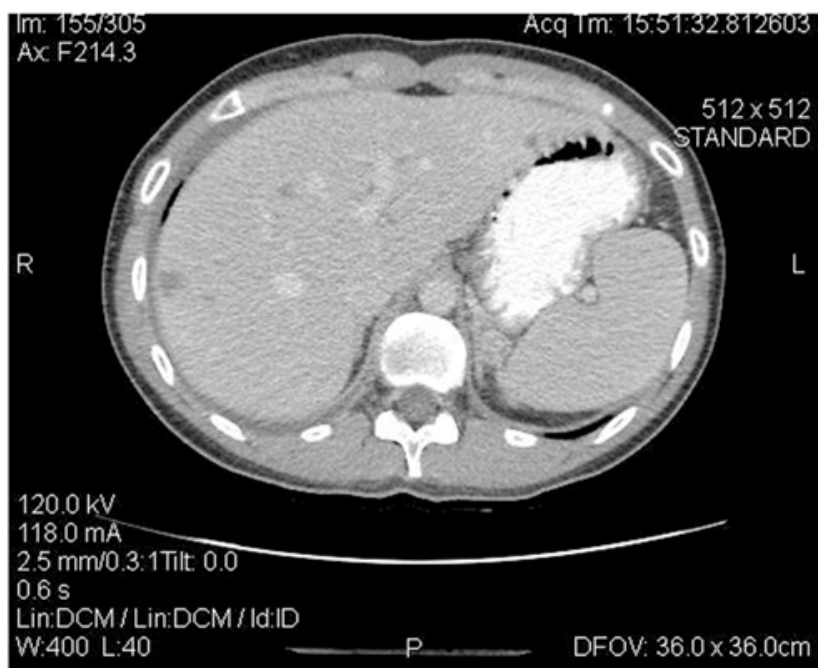

She was commenced on multiple chemotherapeutic agents including Zoledronic acid, Goserelin, FOLFOX and Avastin (Bevacizumab) in conjunction with radiotherapy to the lumbo-sacral spine. She required pleural aspiration on several occasions and underwent pleurodesis for recurrent right sided pleural effusion. Despite all efforts with high dose chemotherapy the tumour rapidly disseminated to the skin and muscles of her neck, face and arms. She died five months after initial surgery.

\section{Discussion}

Primary retroperitoneal mucinous tumours are rare with sporadic reports in the literature. The aetiology and histogenesis of these tumours remains uncertain. The clinical presentation is variable and patients may have few symptoms until a mass is palpable. Others present with common symptoms such as abdominal pain or discomfort or abdominal distension.

There are a number of hypotheses concerning the origin and histogenesis of PRMTs. One hypothesis suggests that these tumours arise from ectopic ovarian tissue or teratoma with predominant mucinous epithelium ${ }^{[4]}$. Tent et al. concluded that whatever the histogenesis of PRMT may be, teratoma from ectopic ovarian tissue or from mucinous metaplasia of the coelomic epithelium, their morphological and biological similarities to ovarian mucinous tumour formation follows similar steps ${ }^{[5]}$. However, the theories about an origin from ectopic ovarian tissue or from an ovarian teratoma cannot account for a tumour arising in a male patient ${ }^{[6-10]}$. A further proposal was that the retroperitoneal cyst arises from the remnants of specialised mesothelial cells of the urogential ridge ${ }^{[11]}$. It has also been hypothesized that the tumour arises from invagination of the peritoneal epithelium with subsequent metaplasia during embryonic growth ${ }^{[12]}$.

In this case, the adenocarcinoma arose in a precursor in-situ lesion characterised by extensive high grade dysplasia, but with focal areas resembling mucinous cystadenoma. There was no pathological evidence of pre-existing intestinal 
duplication. The stroma did not exhibit ovarian features morphologically, but stromal cells expressed oestrogen receptor immunohistochemically, an occurrence which has been noted previously ${ }^{[2]}$. The findings in our case do not specifically favour any of the proposed hypotheses for the histogenesis of PRMT. Although the stromal oestrogen receptor expression might raise the possibility of ectopic ovarian tissue, the overall morphology was not typical of ovarian stroma.

Pre operative diagnosis of PRMTs can be difficult, as tumour markers such as CEA, CA-125 and Ca19-9 may be normal and lack specificity. Cross-sectional imaging by ultrasonography, CT or MRI helps to define and characterise anatomical relationships and any evidence of metastatic spread. In recurrent or metastatic disease tumour markers may be elevated and can be useful in monitoring response to chemotherapy.

In the current case Ca-125 and CA19-9 rose dramatically and imaging confirmed widespread metastases.

It has been stated by Yang et al. ${ }^{[13]}$ a PRMT should be suspected when a cystic lesion displacing colon, kidney or ureter is noted on imaging.

Surgical complete excision of PRMT is advocated for accurate diagnosis and curative management in most cases. There is ongoing controversy concerning the need for, and benefit of, extensive surgery in female patients including hysterectomy and oophorectomy due to one hypothesis assuming ovarian origin of PRMTs ${ }^{[14,15]}$.

The use and benefits of adjuvant chemotherapy for PRMTs is debateable. Lee et al. reported the use of adjuvant chemotherapy in five patients with 3 of the 5 developing recurrence or metastasis within 4 to 21 months after initial surgery ${ }^{[16]}$. Some have advocated the use of chemotherapy if the tumour ruptured during surgery or was invading adjacent structures. In the current case the tumour was removed completely intact (see Figure 2) and was not invading surrounding structures. Despite this the patient re-presented within eight weeks with wide spread metastasis and failed to respond to aggressive chemotherapy.

In conclusion, primary retroperitoneal mucinous tumours are rare with ongoing uncertainty on the tissue of origin, optimal management and clinical behaviour. The histological heterogeneity and metastatic potential of these tumours warrant careful histopathological analysis and follow up. Adjuvant chemotherapy should be considered if PRMT is of malignant type but despite this some tumours are biologically very aggressive and rapidly fatal. Ongoing research is warranted to optimize outcomes in these rare tumours, predominantly affecting young women.

\section{References}

[1] Roth LM, Ehrlich CE. Mucinous cystadenocarcinoma of the retroperitoneum. Obstet Gynecol. 1977; 49: 486-488. PMid: 854250.

[2] Roma AA, Malpica A. Primary retroperitoneal mucinous tumours - A clinicopathologic study of 18 cases. Am J Surg Pathol. 2009; 33(4): 526-533. PMid: 19092632. http://dx.doi.org/10.1097/PAS.0b013e3181909018

[3] Bifulco G, Mandato VD, Giampaolino P, et al. Huge primary retroperitoneal mucinous cystadenoma of borderline malignancy mimicking an ovarian mass: Case report and review. Anticancer Research. 2008; 28: 2309-2316. PMid: 18751411.

[4] Papadogiannakis N, Gad A, Ehliar B. Primary retroperitoneal mucinous tumour of low malignant potential: histogensis aspects and review of the literature. APMIS. 1997; 105(6): 483-486. PMid: 9236866. http://dx.doi.org/10.1111/j.1699-0463.1997.tb00597.x

[5] Tenti P, Carnevali L, Tateo S, et al. Primary mucinous cystadenocarcinoma of the retroperitoneum: two cases. Gynecol Oncol. 1994; 55: 308-312. PMid: 7959300. http://dx.doi.org/10.1006/gyno.1994.1295

[6] Thamboo TP, Sim R, Tan S-Y, et al. Primary retroperitoneal mucinous cystadenocarcinoma in a male patient. J Clin Pathol. 2006; 59: 655-657. PMid: 16731606. http://dx.doi.org/10.1136/jcp.2005.030122

[7] Green JM, Bruner BC, Tang WW, et al. Retroperitoneal mucinous cystadenocarcinoma in a man: case report and review of the literature. Urol Oncol. 2007; 25: 53-55. PMid: 17208139. http://dx.doi.org/10.1016/j.urolonc.2006.02.015

[8] Thamboo TP, Sim R, Tan SY, et al. Primary retroperitoneal mucinous cystadenocarcinoma in a male patient. J Clin Pathol. 2006; 59: 655-657. PMid: 16731606. http://dx.doi.org/10.1136/jcp.2005.030122 
[9] Motoyama T, Chida T, Fujiwara T, et al. Mucinous cystic tumor of the retroperitoneum: a report of two cases. Acta Cytol. 1994; 38: 261-266. PMid: 8147222.

[10] Hrora A, Reggoug S, Jallal H, et al. Primary retroperitoneal mucinous cyst-adenocarcinoma in a male patient: a case report. Cases Journal. 2009; 2: 7196. PMid: 19918513. http://dx.doi.org/10.4076/1757-1626-2-7196

[11] Nelson H, Benjamin B, Aberty R. Primary retroperitoneal mucinous cystadenocarcinoma. Cancer. 1988; 61: $2117-2121$. http://dx.doi.org/10.1002/1097-0142(19880515)61:10<2117::AID-CNCR2820611031>3.0.CO;2-X

[12] Subramony C, Habibpour S, Hashimoto LA. Retroperitoneal mucinous cystadenoma. Arch Pathol Lab Med. 2001; 125: 691-694. PMid: 11300948.

[13] Xu F, Huang Y, Yang J. Primary Retroperitoneal Carcinosarcoma in a Child: A Case Report. [In eng]. World journal of surgical oncology. 2010; 8: 99. PMid: 21087479. http://dx.doi.org/10.1186/1477-7819-8-99

[14] Lee IW, Ching KC, Pang M, et al. Two cases of primary retroperitoneal mucinous cystadenocarcinoma. Gynecol Oncol. 1996; 63: 145-150. PMid: 8898186. http://dx.doi.org/10.1006/gyno.1996.0295

[15] Kessler TM, Kessler W, Neuweiler J, et al. Treatment of a case of a primary retroperitoneal mucinous cystadenocarcinoma: is aduvent hysterectomy and bilateral salpingo-oophorectomy justified? Am J Obstet Gynecol. 2002; 187: 227-232. PMid: 12114915. http://dx.doi.org/10.1067/mob.2002.119809

[16] Lee SA, Bae SH, Ryoo HM, et al. Primary retroperitoneal mucinous cystadenocarcinoma: a case report and review of literature. Korean J Intern Med. 2007; 22: 287-291. PMid: 18309690. http://dx.doi.org/10.3904/kjim.2007.22.4.287 